\title{
AS DROGAS E OS CENÁRIOS DE LAZER
}

Recebido em: $17 / 11 / 2013$

Aceito em: 23/07/2014

\author{
Liana Romera ${ }^{1}$ \\ Universidade Federal do Espírito Santo \\ Vitória - ES - Brasil
}

RESUMO: Este artigo tem por objetivo destacar alguns elementos que permeiam a relação entre vivências do lazer e consumo de drogas lícitas e ilícitas. Destaca a atualidade destas relações ressaltando a necessidade de abandonar antigos tabus e preconceitos que estigmatizam os usuários, numa compreensão que não distingue os diferentes usos e as distintas substâncias. A partir de pesquisa bibliográfica foram analisadas publicações desenvolvidas no Brasil e Espanha acerca do consumo de drogas em situações de lazer na área das Ciências Sociais que contribuíram para as reflexões aqui apresentadas. Faz-se imperativo o debate acadêmico no campo do lazer a partir de um cenário que contemple os diferentes usos e usuários de drogas lícitas e ilícitas bem como a necessidade de ampliação das pesquisas sobre o tema e o estabelecimento dos diálogos interdisciplinares com propósito de subsidiar políticas de lazer e de prevenção.

PALAVRAS CHAVE: Atividades de Lazer. Usuários de Drogas. Consumo.

\section{DRUGS AND SCENARIOS LEISURE}

ABSTRACT: This article aims to highlight some elements that permeate the relationship between experiences of leisure and consumption of licit and illicit drugs. Highlights the relevance of these relations emphasizing the need to abandon old prejudices and taboos that stigmatize users, an understanding which does not distinguish the different uses and different substances. From literature publications developed in Brazil and Spain on drug use in leisure situations in the Social Sciences that contributed to the ideas presented here were analyzed. It will be imperative to the academic debate in the field of leisure from a scenario that covers the different uses and users of licit and illicit drugs and the need for expansion of research on the topic and the establishment of interdisciplinary dialogues with purpose of subsidizing policies leisure and prevention.

KEYWORDS: Leisure Activities. Drug Users. Consumption.

O presente artigo trata da relação cada vez mais próxima entre as vivencias de lazer e o consumo de substancias lícitas ou ilícitas, especialmente por uma parcela do

\footnotetext{
1 Professora da Universidade Federal do Espírito Santo. Coordenadora do Grupo de Pesquisa ANDALUZ/CNPq.
} 
público jovem. Tal discussão tomará por base os resultados de estudos desenvolvidos por pesquisadores brasileiros e europeus e, a partir de suas conclusões apontam duas importantes questões sobre duas funções fundamentais que tem o lazer para $o$ aprofundamento das questões relativas a esta temática. Por uma lado temos os eventos de lazer noturno como espaço privilegiado para o consumo de drogas e, por outro, o próprio lazer como lócus de estudos acerca dos usos, uma vez que este é caracterizado pela busca do prazer e liberdade.

A relação do lazer com o consumo de drogas lícitas e ilícitas ainda é pouco discutida nos eventos científicos da área do lazer, especialmente no Brasil, não obstante o grande interesse que o tema vem despertando na sociedade, possivelmente por conta do destaque que o assunto ganha na imprensa nacional e internacional.

O hábito de consumir substâncias psicoativas é tão antigo quanto a própria humanidade. Presente em diferentes culturas, sociedades e épocas, o consumo de drogas envolve uma complexidade que deve ser considerada ao se debater o tema. Além da necessidade de discutir a questão com a intermediação das diferentes áreas do conhecimento, é preciso ainda que se despoje de qualquer postura moralista, preconceituosa ou de julgamentos maniqueístas, que somente contribuem para fortalecer os estigmas dos usuários e alargar a distância do debate sério e racional.

Embora se perceba o aumento no número de usuários de drogas e a presença de novas substâncias psicoativas no cenário social, a temática ainda representa assunto complexo e controverso, cujas discussões e abordagens, quando distanciadas do conhecimento científico, resultam em conclusões equivocadas e contraproducentes que em nada contribuem para a compreensão do problema, para a proposição de políticas públicas ou para a diminuição das consequências negativas que o uso produz. 
Ancorado na abordagem sociológica, o presente texto tem por objetivo destacar alguns elementos básicos que permeiam as discussões dessa área, visando levantar reflexões acerca do uso de drogas e sua aproximação com a temática do lazer.

Romera (2008, p. 30) defende que para estudar o uso e o usuário de drogas devese considerar uma tríade formada pelo tipo de substância, o indivíduo e o contexto social no qual ele se insere, uma vez que a combinação desses fatores imprimirá toda a diferença nos distintos modos de uso, como do seu significado para o usuário. Considerar a inter-relação entre o tipo de substância procurada, o indivíduo e o modo como este irá relacionar-se com a droga significa contemplar o usuário valendo-se de uma abordagem biopsicossocial preocupada com o ser humano e seu bem-estar.

No início de aprofundado estudo acerca da existência das drogas na história da humanidade, Escohotado (1996) apresenta a seguinte conceituação do termo:

Por droga - psicoativa ou não - seguimos entendendo o que há dois mil anos pensavam Hypócrates e Galeano, pais da medicina científica: uma substância que em vez de ser vencida pelo corpo (e assimilada como simples nutrição), é capaz de vencê-lo, provocando - em doses ridiculamente pequenas se comparadas com os outros alimentos grandes mudanças orgânicas, anímicas e de ambos os tipos (p.9).

Partindo do princípio de que o uso de drogas representa um comportamento milenar, faz-se importante considerar que tal uso vem ocorrendo durante os séculos de diferentes modos, por grupos diversos, com finalidades variadas (medicinais, religiosas, recreativas) e em diferentes contextos sociais, alternando a classificação do lícito e do ilícito.

Em estudo sociológico referente a drogas, Bergeron (2012) destaca que a distinção entre drogas lícitas e ilícitas é permeada por uma fronteira simbólica que muda seu foco de tempos em tempos, de acordo com os interesses financeiros da época. Segundo Bergeron, o papel determinante do Direito moderno na definição do que seja 
droga lícita e ilícita faz com que nem toda substância psicoativa seja classificada como entorpecente pela legislação. Afirma Bergeron (2012, p. 8) que a “a categorização social de uma substância como 'droga' e sua classificação jurídica como 'entorpecente' dependem muito mais de uma convenção social e cultural”.

As áreas das Ciências Sociais, como Antropologia e Sociologia, passaram a interessar-se pela temática das drogas na segunda metade do século $\mathrm{XX}$, com trabalhos de Becker (1966); MacRae (2004); Romani (1999) coincidindo com o período em que o consumo torna-se massificado nas sociedades ocidentais. No campo das Ciências Sociais, os primeiros estudos enfocaram o uso de drogas como "formas particulares de desvio", entendidas como uma calamidade social, tratado com preconceitos, moralismos fortalecedores de estigmas dos usuários, vinculando o uso à delinquência, relacionando, de modo geral, o usuário de drogas à falta de caráter, malandragem e marginalidade.

Essa forma de abordar a questão, com uma visão reducionista que compreende todos os usuários de forma homogênea, que rotula a todos como incapacitados e moralmente frágeis, somente contribui para o aumento do estigma, o preconceito e o distanciamento de melhor compreensão dos usos, dos usuários e seus contextos.

Bergeron ressalta que o usuário de drogas era chamado de drogado, termo pejorativo, pois era considerado pela sociedade como alguém que perdeu as qualidades essenciais que fazem um sujeito social digno e respeitável. Os primeiros estudos sociológicos do uso de drogas foram, de modo geral, realizados com grupos minoritários e economicamente desfavorecidos, construindo-se uma herança histórica que dá origem aos preconceitos e alimenta opiniões distorcidas sobre o tema até os dias atuais.

Além de tratado como temática relacionada à delinquência e marginalidade, o uso de drogas era também compreendido como uma escolha de pessoas fracas, "um 
caminho sem volta", "um sinal de fracasso pessoal", numa construção social de homogeneização dos usuários de drogas.

Acerca da tendência de homogeneização dos usos e usuários de drogas, Espinheira (2004, p. 11) apresenta uma advertência que, mesmo parecendo óbvia, é bastante pertinente:

Os usuários de drogas têm em comum, o que é evidente, o uso de drogas. Podemos, portanto, afirmar que as formas de uso e os significados diferem de indivíduo para indivíduo, assim como de grupo para grupo dentro de uma mesma cultura, e são mais distintos ainda quando comparamos culturas contrastantes.

Os usuários de drogas não pertencem a uma única categoria, não são semelhantes nem mesmo pelo fato de usarem o mesmo tipo de substância. Ainda afirma Espinheira (2004, p. 19):

[...] o uso de drogas depende mais do usuário do que da droga que usa, e isso significa que não se pode atribuir à droga uma autonomia em relação ao indivíduo ou mesmo ao contexto social, mas, ao contrário, perceber o indivíduo e seu contexto para compreender o tempo e os espaços das drogas em sua vida.

Além de padrões de consumo diferentes, há também níveis de envolvimento distintos. Modos de relacionar-se com a droga e seu contexto particularizado variam de um para outro indivíduo, devendo-se, portanto, considerar que um usuário ocasional não é o mesmo que um usuário regular $^{2}$, assim como um dependente químico não é sinônimo de traficante. Embora os estudos mostrem que a linha divisória que separa o uso regular da dependência seja bastante tênue e varie de um para outro usuário, nem todos os usuários irão desenvolver a dependência e usar drogas indefinidamente ou de forma descontrolada. Da mesma maneira, é uma parcela muito pequena do universo de

\footnotetext{
${ }^{2} \mathrm{O}$ uso de drogas está classificado em experimental, ocasional, habitual e dependência.
} 
usuários de drogas que se envolve com o tráfico ou outras modalidades de contravenção.

Aos poucos os focos de análise das pesquisas sobre consumo de substâncias psicoativas foram se distanciando das abordagens que exaltavam somente o desvio e passaram a considerar outras relações entre a droga e o usuário, como o uso relacionado à busca do prazer, hedonismo e seu consumo em contextos menos relacionados aos guetos e mais próximo das situações de lazer.

Sobre tais mudanças, Bergeron (2012, p. 8) adverte que os novos tempos trazem novos usos; porém, alguns resquícios ainda habitam o imaginário social:

Embora o consumo recreativo de drogas, ligado à diversão e à festa, forme cada vez mais um dos aspectos mais significativos do quadro que descreve o uso de drogas no início do século XXI, o imaginário social habitualmente associado à droga e à toxicomania é sombrio: o fato de experimentar esses produtos, ou pelo menos alguns deles, é com muita frequência concebido como a mãe potencial do vício, do crime, da morbidez e da marginalidade.

O estreitamento da relação entre consumo de droga, diversão e a aproximação das discussões do lazer podem contribuir para o distanciamento das abordagens estigmatizantes e da marginalidade dos usuários, exigindo olhares e estudos mais próximos da atual realidade que envolve os diferentes usos.

\section{Drogas e lazer}

Se no início dos estudos sociológicos sobre o uso de drogas prevaleciam abordagens sobre a relação entre consumo, marginalidade e delinquência ${ }^{3}$, mais recentemente as pesquisas apontam outras aproximações entre uso de drogas lícitas e

\footnotetext{
${ }^{3}$ No capítulo "Droga, delinquência e criminalidade", do livro Sociologia da droga, Bergeron questiona se a prática delinquente é responsável pelo uso de drogas ou o contrário? Sugere o autor haver entre os temas uma relação complexa. Com base em estudos sociológicos, afirma que o nível de delinquência dos usuários encontra-se mais ligado à existência de uma delinquência anterior e à variável intensidade do que ao uso regular ou dependente. Para Bergeron, quando ambas se dão de modo simultâneo, favorece a explicação de que o uso se deu por diversos outros fatores sociais.
} 
ilícitas em diferentes contextos, com predominância nos espaços de lazer e também pela busca de prazer. Sobre essa abordagem, podem ser citados: Baptista et al. (2002); Calafat et al. (2008); Hunt e Evans (2003); Jimenez; Diaz e Ruiz (2005); Martins (2006); Romera (2008); Scivoletto e Morishita (2001); entre outros.

Considerando haver diferentes drogas, para finalidades diversas, conforme sinaliza a história da humanidade, há que se ater também ao fato de que existem diferentes níveis de uso e de envolvimento com as substâncias. Nem todo uso de psicoativos é originado da mesma lógica ou motivação.

Se a droga, seu uso e seu comércio conhecem uma expansão sem precedentes a partir de meados do século XIX, mas sobretudo na virada dos dois séculos, é preciso esperar a segunda metade do século XX para que o consumo, do modo como o conhecemos nos dias atuais, encontre suas premissas verdadeiras (BERGERON, 2012, p. 28).

Defende Bergeron coexistirem ao menos dois grupos distintos de usuários de drogas, um deles formado pelas camadas menos favorecidas da sociedade e mais facilmente vinculados ao consumo marginal, estreitando a relação (ainda que superficialmente) da droga com a violência social e marginalidade.

Outro grupo é formado pela parcela mais favorecida economicamente, cujo uso de drogas está diretamente relacionado ao hedonismo e tem por principais contextos sociais as "baladas", festas e demais modalidades de lazer noturno.

$\mathrm{Na}$ atual relação estabelecida com a droga, especialmente pelo público jovem (mas não unicamente), o lazer representa ao menos dois papéis fundamentais para o aprofundamento das questões afetas à temática:

1- A vivência do lazer, sobretudo aquele desenvolvido em eventos noturnos, foi detectada como contexto privilegiado para o uso de drogas, apontada em inúmeras e recentes pesquisas que serão aqui apresentadas. 
2 - O lazer transforma-se relevante lócus de estudos sobre o uso de drogas, sugerindo não somente maior envolvimento com a temática, mas também a necessidade de estreitar o diálogo entre as Ciências Sociais e a Saúde, fortalecendo abordagens multi e interdisciplinares para melhor compreensão do assunto.

Assim, serão mencionadas algumas pesquisas cujo objetivo consistiu em analisar a relação entre consumo de diferentes drogas em distintos contextos de lazer, ressaltando que, ainda que reconhecendo a relevância dos trabalhos já desenvolvidos para analisar a relação drogas e lazer - realizados especialmente por grupos de pesquisa da Europa e Estados Unidos -, é preciso admitir que ainda há muito por fazer e desvendar nesse campo sociológico.

Há que se considerar também que o fato de abordar o tema sem preconceitos moralistas não significa nenhum tipo de apologia do uso de drogas, considera-se aqui que qualquer uso representa risco à saúde e à vida do indivíduo e da sociedade.

Trata-se tão somente de olhar para uma questão social sem incorrer em julgamentos morais, na tentativa de melhor compreender o tema e visando apresentar subsídios que possam amenizar os impactos do uso de drogas para os usuários.

\section{Contextos de lazer e consumo de drogas}

Importantes pesquisadores têm buscado compreender os fatores que envolvem o uso de drogas com base em estudos desenvolvidos em contextos de lazer. Associações entre álcool e vida sexual, drogas sintéticas e alteração das percepções, além da busca hedonista, são observadas nas conclusões de trabalhos que enfocam o tema.

Calafat et al. (2008) estudaram os modos de diversão noturna de jovens europeus e classificaram as novas formas de vivência do lazer dessa parcela da sociedade como um fenômeno social importantíssimo no mundo ocidental. O modelo 
recreativo das noites e dos finais de semana desses jovens fora denominado de Modelo de Diversão Hegemônico (MDH). O referido modelo se propagou de forma acelerada na Europa, desde o início da década de 1980, em virtude, em grande parte, dos modelos de diversão noturna criados nos lugares turísticos do Mediterrâneo, que rapidamente se espalharam por outros continentes, influenciando de modo significativo a forma de viver o lazer de uma parcela da juventude. Nesse modelo de diversão, o consumo de drogas lícitas e ilícitas é constante e, embora não seja unanimidade entre seus frequentadores, apresenta uma parte significativa de consumidores, tanto das substâncias lícitas, como álcool e tabaco, quanto ilícitas, como maconha, cocaína, ecstasy, entre outras.

Calderon et al. (2012) analisaram os efeitos associados ao policonsumo ${ }^{4}$ de drogas em festas raves na Espanha e fizeram a classificação dessa modalidade de festa cujas principais características são a música eletrônica, realizadas geralmente por mais de uma noite em grandes espaços na zona rural ou em lugar de difícil acesso, como também a auto-organização e a propaganda, que não ocorrem pelos canais convencionais de divulgação. Segundo Calderon et al. (2012, p. 39), "Diferentes estudos têm mostrado que o consumo e policonsumo de drogas em raves é superior ao que se encontra em outros contextos recreativos". Entre os resultados apontados na pesquisa, nessa modalidade de lazer, os autores destacam:

Todos os participantes consumiram uma ou mais drogas. $20,1 \%$ dos participantes consumiram seis ou mais drogas, $45,6 \%$ consumiram quatro a cinco drogas. Ainda de acordo com os autores, a prevalência de uso, em ordem crescente, foi álcool, maconha, speed, ecstasy (MDMA), cocaína, ketamina, LSD (CALDERON et al., 2012, p. 45).

\footnotetext{
${ }^{4}$ Consumo simultâneo de diferentes substâncias psicoativas com objetivo de associação dos efeitos provocados por cada uma delas.
} 
Buscando melhor compreender o usuário de drogas sintéticas nessa modalidade de divertimento, os autores detectaram os principais efeitos percebidos pelos usuários e afirmam:

[...] os efeitos mais percebidos foram sentimento de euforia, bemestar, felicidade, conexão com a música, potencialização dos sentidos e melhor comunicação com os demais [...] dentre os efeitos negativos percebidos destacaram-se cansaço, bruxismo, falta de concentração, perda do sono, depressão (CALDERON et al., 2012, p. 45).

Pesquisando outros contextos recreativos noturnos do público jovem, Calafat et al. (2008, p. 37) exploraram os modos como os jovens espanhóis se relacionam com o uso de drogas e a sexualidade, objetivando a classificação de cada tipo de droga e seu papel na experimentação da sexualidade nessa modalidade de lazer. Concluíram os pesquisadores que o álcool é a droga mais popular e a que maiores vantagens oferece ao consumidor entre quatro modalidades de experimentação sexual analisadas: “[...] facilitar o encontro sexual, envolver-se em experiências mais arriscadas, aumentar a excitação e prolongar a relação sexual”.

No Brasil, o consumo de ecstasy foi estudado por Baptista et al. (2002), que identificaram que os clubes noturnos e as raves são os principais contextos de uso de drogas, ganhando mais força na década de 1990. Alegria, autoconfiança, sociabilidade e euforia promovidas pela droga são os principais efeitos buscados nesse consumo.

Acerca do perfil do frequentador desse tipo de lazer aliado ao consumo do ecstasy, Baptista et al. (2002) revelam ser jovens adultos com boa formação escolar, inseridos no mercado de trabalho, pertencentes às classes sociais privilegiadas, sendo poliusuários de drogas, coincidindo então com os achados de Calderon et al.

O crescente aumento do número de usuários de drogas é verificado na mesma proporção da descoberta das novas substâncias, especialmente as sintéticas. Apesar desse aumento da oferta das drogas sintéticas consumidas em contextos de lazer, no 
Brasil, tanto quanto nos países da Europa, o álcool representa ainda a droga mais consumida em situações de lazer, conforme apontam os resultados do Relatório brasileiro sobre drogas (BRASIL, 2009) ${ }^{5}$, muito embora ele não seja socialmente percebido como droga, possivelmente por figurar entre as substâncias lícitas.

Alguns números apresentados no relatório apontam o álcool como principal substância de uso dos brasileiros. Embora o documento aponte a prevalência de uso durante a vida, o ano e o mês, com base nas coletas realizadas em 2001 e 2005, será destacado somente o uso no ano referente a 2005, a fim de apresentar os dados mais recentes do uso de drogas entre os brasileiros.

A prevalência do uso de álcool no ano foi de $49,8 \%$, enquanto o uso de maconha ficou em 2,6\%, cocaína com $0,7 \%$, e estimulantes também com $0,7 \%$. Os dados confirmam o maior consumo de álcool quando comparado a outras drogas, ratificando a necessidade de políticas do álcool mais eficazes. Outra importante questão a ser considerada está no padrão de beber, pois o consumo excessivo é constantemente verificado na literatura.

A expressão surgida entre os pesquisadores da área, "beber ao extremo", assim como o termo binge, definido como o consumo, em uma só ocasião, de cinco doses ou mais para homens e quatro doses ou mais para mulheres, ilustram a relação que uma parcela da sociedade estabelece com a bebida e o faz, preferencialmente, em momentos de lazer.

Beber ao extremo e binge representam termos que abarcam um modo de consumo no qual beber em excesso não pode ficar restrito a medidas de quantidade e à

\footnotetext{
5 Os dados considerados referem-se ao I e ao II Levantamento Domiciliar sobre o Uso de Drogas Psicotrópicas no Brasil, realizados pela Secretaria Nacional de Políticas sobre Drogas (SENAD) em convênio com a Universidade Federal de São Paulo (UNIFESP), Departamento de Psicobiologia, Centro Brasileiro de Informações sobre Drogas Psicotrópicas (CEBRID), nos anos de 2001 e 2005, respectivamente. A população estudada é constituída por brasileiros com idade entre 12 e 65 anos, residentes em cidades com mais de 200 mil habitantes no Censo de 2000, configurando 108 cidades.
} 
frequência ou à embriaguez em si, pois envolve uma série de contextos sociais e culturais nos quais tal comportamento é cada vez mais evidente (MARTINIC; MEASHAM, 2011).

Outra expressão que caracteriza o uso de substâncias psicoativas por parte de uma parcela da juventude durante as "baladas" é o "salir de marcha", expressão espanhola que caracteriza o consumo exagerado de alguma droga lícita ou ilícita. Numa mostra com estudantes de 14 a 18 anos de idade, observou-se que mais da metade havia "salido de marcha" no último mês. Nessas saídas, 44,8\% dos jovens beberam ao extremo, 26,4\% fumaram maconha, 3,8\% consumiram cocaína e 1,4\% usou ecstasy.

O mais recente estudo brasileiro, também desenvolvido pelo CEBRID analisou os hábitos do paulistano nas baladas noturnas e detectou que $56 \%$ dos frequentadores desta modalidade de lazer declararam o intuito de ficar bêbado e o fazem por meio do ‘binge drinking’. (FOLHA DE SÃO PAULO, 2013).

Os estudos brasileiros e europeus apontam sempre um consumo maior de drogas lícitas em comparação às ilícitas, embora os alardes da mídia e das políticas sobre drogas tenham como foco os usuários de substâncias ilícitas.

\section{O lazer como lócus de estudos sobre os usos de drogas}

Considerando as mudanças ocorridas no perfil do uso de drogas, mudanças de contexto e predominância dos espaços recreativos, o lazer passa a representar importante lócus de estudos da sociedade e consequentemente do uso de drogas. Nesse sentido, Magnani (2000, p. 25) afirma:

O lazer não é apenas um campo promissor de atividades, de negócios, de intervenção: é também um campo a partir do qual se pode pensar a sociedade atual com seus grupos, sua sociabilidade e seus conflitos. Suporte de múltiplos significados, o lazer oferece uma via de acesso ao conhecimento dos impasses e possibilidades que se abrem na sociedade contemporânea. 
Acredita ainda o antropólogo que "[...] a partir do lazer é possível pensar a sociedade e refletir sobre valores mais gerais, pois ele não está desvinculado dos demais planos da vida social”" (MAGNANI, 2000, p. 22).

Também para Pais (1990, p. 591), destacado sociólogo português, que tem nas culturas juvenis seu tema de estudos, as abordagens acerca desse conjunto de comportamentos juvenis apresentam-se diretamente ligadas às questões do tempo livre, sendo, portanto, “[...] no domínio do lazer que as culturas juvenis adquirem uma maior visibilidade e expressão".

As possibilidades investigativas que essa área de conhecimento apresenta legitimam destacá-la como importante campo de estudos interdisciplinares da vida, dos costumes e das diversas manifestações sociais, entre elas o uso de drogas.

\section{Finalizando}

O uso de drogas representa um costume milenar que atravessou a história e os povos, sendo concebida de acordo com os interesses de cada época. Usos medicinais, religiosos e recreativos representam formas distintas de relação do homem com as substâncias psicoativas. Mudanças nos contextos de usos, nos usuários, nas intenções devem ser consideradas para que a questão possa ser mais bem compreendida.

Os modos de ocupação do tempo livre passam a refletir os modos de vida de um tempo social; assim, cabe analisar os tempos atuais e as formas de ocupação do tempo pelos diferentes grupos etários, étnicos, de gênero, classe social, intelectual etc.

Distinguir os diferentes usos de drogas e seus usuários sem a visão homogeneizada representa uma nova postura exigida sobre aqueles que queiram focar nessa direção. 
Desvincular o uso e o usuário de drogas da marginalidade e da condenação antecipada, compreendendo que, ainda que se use a mesma substância, cada indivíduo é movido por motivações e necessidades particulares.

Compreender as novas modalidades de usos de drogas e sua associação com os contextos de lazer significa delegar a esse campo do conhecimento um status de relevância para entendimento dos fenômenos que envolvem os usos de drogas, possibilitando subsidiar políticas públicas de lazer e de prevenção.

\section{REFERÊNCIAS}

BAPTISTA, M.C. et al. O uso de êxtase (MDMA) na cidade de São Paulo e imediações: um estudo etnográfico. Jornal Brasileiro de Psiquiatria, Rio de Janeiro, v. 51, n. 2, p. 81-89, 2002.

BECKER, H.S. Outsiders- Studies in the Sociology of Deviance. New York: Free Press, 1966.

BERGERON, H. Sociologia da droga. Tradução Tiago José Risi Leme. São Paulo: Ideias e Letras, 2012.

Presidência da República. Secretaria Nacional de Políticas sobre Drogas. Relatório brasileiro sobre drogas. Secretaria Nacional de Políticas sobre Drogas; IME USP; organizadores Paulina do Carmo Arruda Vieira Duarte, Vladimir de Andrade Stempliuk e Lúcia Pereira Barroso. Brasília: SENAD, 2009. 364p.

CALAFAT; A. et al. Qué drogas se prefieren para las relaciones sexuales en contextos recreativos. Adicciones, Palma de Mallorca, Socidrogalcohol, v. 20 n. 1, p. 37-48, 2008.

CALDERON, F.F. et al. Efectos asociados al policonsumo de drogas in fiestas raves. Health and Addictions: salud y drogas, INID, v. 12, n. 1, p. 37-59, 2012.

ESCOHOTADO, A. La historia elemental de las drogas. Barcelona: Anagrana, 1996.

ESPINHEIRA, G. Os tempos e os espaços das drogas. In: ALMEIDA, A.R. et al. (Org.). Drogas, tempos, lugares e olhares sobre o seu consumo. Salvador: EDUFBA, CETAD/UFBA, 2004. p. 1-26.

FOLHA DE SÃO PAULO. “56\% dos paulistanos vão á casas noturnas para ficar bêbado". Caderno Cotidiano, página C 5, 2013. 
HUNT, G.; EVANS, K. Dancing and drugs: a cross national perspectives. Contemporary Drugs Problems, Somers, Publications Legais Federais, v. 30, n. 4, p. 779-814, 2003.

JIMÉNEZ, M.V. M.; DIAZ, F.J.R.; RUIZ, C.S. A motivadores de consumo de alcohol em adolescentes: análisis de diferencias inter-género y propuesta de un continuum etiológico. Adicciones, Palma de Mallorca, Socidrogalcohol, v. 17, n. 2, p. 105-120, 2005.

MACRAE, E. Abordagens qualitativas na compreensão do uso de psicoativos. In; Drogas: tempos, lugares e olhares sobre seu consumo, Tavares, L.A , Almeida, AR. B.MacRAe, E., Ferreira,O.S. et al (Org.), Salvador, EDUFBA;CEETAD/UFBA, 2004 pp. 27-48. - NEIP: Disponível em: http://www.neip.info/downloads/t edw9.pdf.

MAGNANI, J.G.C. Lazer, um campo interdisciplinar de pesquisa. In: BRUHNS, H.T.; GUTIERREZ, G.L. (Org.). O corpo e o lúdico. Campinas: Autores Associados, 2000. p. 19-33.

MARTINIC, M.; MEASHAM, F. Nadando com crocodilos: a cultura do beber ao extremo. Routledge - Taylor \& Francis Group, 2011. Disponível em: $<$ http://www.icap.org/LinkClick.aspx?fileticket=D6TZXuWCLNg\%3D\&tabid=212>. Acesso em: maio 2013.

MARTINS, R.A. Uso de álcool, intervenção breve e julgamento sócio-moral em adolescentes que bebem excessivamente. 2006. Tese (Livre-Docência em Psicologia da Educação) - Instituto de Biociências, Letras e Ciências Exatas, Universidade Estadual Paulista, 2006.

PAIS, J.M. Lazeres e sociabilidades juvenis - um ensaio de análise etnográfica. Análise Social, Lisboa, Universidade de Lisboa, vol. 25, n. 108-109, p.591-644, 1990.

ROMANI, O. Las Drogas Sueños y Razones. Barcelona: Editorial Ariel,1999.

ROMERA, L.A. Juventude, lazer e uso abusivo de álcool. 2008. (Tese de Doutorado em Educação Física) - Faculdade de Educação Física, Universidade Estadual de Campinas, Campinas, 2008.

SCIVOLETTO, S.; MORISHITA, R.S. Conceitos básicos em dependência de álcool e outras drogas na adolescência. Jornal Brasileiro de Dependências Químicas, São Paulo, ABEAD, v. 2, supl. 1, p. 30-33, jun. 2001.

\section{Endereço da Autora:}

Liana Romera

Rua Laurentino Proença Filho, 300 apto 501 B Jd da Penha

Vitoria - ES - 29.060-440

Endereço Eletrônico: liromera@uol.com.br 